\title{
PÕHIKOOLI I ASTME ÕPILASTE VALMISOLEK JA SUUTLIKKUS TEHA EMAKEELE E-TASEMETÖÖD ${ }^{1}$
}

\author{
HELIN PUKSAND, ANNE UUSEN
}

\begin{abstract}
Annotatsioon. Eesti elukestva õppe strateegia 2020 (HTM 2014) näeb ette Eesti haridussüsteemi ülemineku üldisele e-hindamisele kõikides kooliastmetes. Selles kontekstis antakse artiklis ülevaade 2019. aasta oktoobris korraldatud e-tasemetöö katsetusest põhikooli I astmes $(\mathrm{N}=249)$, tehes esialgse tulemuste analüüsi põhjal oletusi selle kohta, milline on selles vanuses õpilaste suutlikkus üleminekuks emakeeleoskuse e-hindamisele. Artiklis esitatakse ka ülevaade ülesannete tüüpidest, mis katsetesti tulemuste põhjal osutusid kõige sobilikumaks ja jõukohasemaks, pidades muu hulgas silmas õpilaste oletatavat digipädevust. Analüüsi tulemused näitavad, et põhikooli I astme õpilased saavad e-testi tegemisega hakkama rahuldavalt. Mõnevõrra üllatuslikult selgus, et 3. ja 4. klassi õpilaste tulemused on üsna võrdsed. Kõige lihtsamaks osutusid valikvastustega häälikuõigekirjaülesanne ja ilukirjandusteksti kuulamise ülesanne, kõige raskemaks aga õige sõnavormi lünkülesanne. Ülesannete keskmine lahendusprotsent $(60,4 \%)$ lubab järeldada, et üleminek e-hindamisele põhikooli I astmes on teatud tingimustel võimalik, eriti kui katseülesannete analüüsist lähtudes koostada selleks sobilikud ja õpilaste digipädevuse taset arvestavad ülesanded.
\end{abstract}

Võtmesõnad: e-hindamine, e-tasemetöö, e-test, kujundav hindamine

\section{Sissejuhatus}

Kooliharidus peab andma aluse õpilaste toimetulekule igapäevaelus, et noored saaksid pärast lõpetamist osaleda edukalt tööturul ja ühiskondlikus elus ning neil oleks võimalus jätkata õppimist kogu elu. Seetõttu on põhikooli riiklikus õppekavas (PRÕK 2011) seatud eesmärgiks arendada peale valdkonnapädevuste ka üldpädevusi.

1 Artikli valmimist on toetanud SA Innove projekti LHVEE18267 „Keele ja kirjanduse valdkonna oskustasemete e-hindamise süsteemi arendamine" kaudu. 
Tehnika areng on sellel sajandil olnud väga kiire ja ilma digivahenditeta ei kujuta inimesed enam oma elu ettegi. Seetõttu on Eesti elukestva õppe strateegia 2020 (HTM 2014) üks eesmärke ka Eesti haridussüsteemi üleminek e-hindamisele. Et see oleks mõeldav ja võimalik, on põhikooli riiklikusse õppekavasse (PRÕK 2011) lisatud alates 2014. aastast ka digipädevuse nõue (VV 2014). Siit võiks järeldada, et nendel õpilastel, kes on kooli läinud viimase kuue aasta jooksul, on arendatud peale ainepädevuse ka digipädevust ning digivahendid on nende igapäevased kaaslased kooliski. See tähendab, et e-hindamine võiks olla igati mõistlik. Siiski ei leia põhikooli riiklikust õppekavast ühtki I kooliastme eesti keele õpitulemust, mis oleks seotud digivahendite kasutamisega (vt PRÕK 2011, lisa 1), kuna ainekava ei ole pärast 2014. aastat muudetud.

2014. aastal alustati eesti keele e-tasemetööde katsetamisega II kooliastmes. Katsetööde analüüs lubas jätkata nii e-tasemetööde kui ka e-eksamite arendamist. Alates 2016. aastast tehaksegi kõiki II kooliastme tasemetöid elektrooniliselt. Seevastu I kooliastmes on eesti keele emakeelena tasemetööd seniajani toimunud paberil. Kuni siinses artiklis kirjeldatud katsetuseni ei ole emakeele e-teste I kooliastmes teha proovitud. Arvatavasti on põhjuseks õigustatud arvamus, et I astme õpilastel ei ole e-tasemetöö sooritamiseks veel piisavat digipädevust.

Eelnevast lähtudes seati uurimuse eesmärgiks teada saada, kuidas I kooliastme õpilased sooritavad e-ülesandeid. Eesmärgi täitmiseks otsiti vastuseid järgmistele uurimisküsimustele.

1. Mis ülesandetüübid on e-testis kasutamiseks sobivaimad ja õpilastele jõukohaseimad, mõeldes õpilaste võimalikele digipädevustele?

2. Missugune on I kooliastme õpilaste digipädevus nende endi hinnangul?

\section{E-hindamise põhimõte, eelised ja probleemid}

Üldhariduskoolis kasutatakse hindamist, et toetada õppimist, selgitada välja, kas õpitulemused on omandatud, ja hinnata õppekava (van der Vleuten jt 2015). Hindamise tähtsaim eesmärk on anda tagasisidet nii õpilasele kui ka õpetajale, et õppimine muutuks tõhusamaks, püsivamaks ja emotsionaalselt rahuldust pakkuvamaks (Jürimäe jt 2014: 56). E-hindamisega saab arvutit kasutada nii kokkuvõtlikuks, kujundavaks kui ka 
diagnoosivaks hindamiseks (Jordan 2013). Seejuures võib e-hindamine olla eri vormis, nagu näiteks lihtsalt pabertestide digiteeritud versioonid või veebitestid, mis sisaldavad valikvastustega ja probleemilahendusoskuse hindamist võimaldavaid ülesandeid. Üldises mõttes tähendab e-hindamine hindamise toetamist arvuti abil, näiteks kasutades veebipõhiseid hindamisvahendeid (Alruwais jt 2018).

Enamik uurijaid (vt nt Reju, Adesina 2009: 4) on jõudnud arvamusele, et e-hindamine peaks otsast lõpuni toimuma elektrooniliselt, alustades ülesannete koostamisest ja nende esitamisest õpilastele ning lõpetades vastuste hindamise ja tulemuste analüüsiga. Tegelikkuses seab see aga e-hindamisele suuri piiranguid, kuna avatud vastustega küsimusi ja muid kirjutamisülesandeid ei ole vähemalt eesti keeles veel võimalik arvutiga hinnata.

Et digipöörde raames koostatavate e-testide ja/või e-tasemetööde kaudu hinnatavate aspektide hulk on suur, eriti keele ja kirjanduse valdkonnas, siis pole vähemalt esialgu võimalik e-teste koostada selliselt, et kõik aspektid ja ülesanded oleksid arvutihinnatavad. Näiteks ei saa õpilaste vabavastustega kirjutistes kirjutamisoskuse taseme määramiseks vajalikke aspekte arvutiga hinnata, vaid seda peavad tegema endiselt selleks koolitatud õpetajad, nagu ka põhjendamist nõudvate küsimuste korral.

Eri kirjandusallikates on esile toodud e-hindamise eeliseid õpilaste, õpetajate, institutsioonide ja hariduslike eesmärkide vaatenurgast. Õpilased peavad e-hindamise üheks oluliseks eeliseks kasutusmugavust ja huvitavat testikeskkonda, mida saab kergesti ja kiirelt kasutada (kui keskkond on tuttav). E-hindamine pakub või vähemalt peaks pakkuma ka kohest tagasisidet, mis motiveerib õppimist tõhustama. (Gilbert jt 2011: 9-10) Olenevalt e-hindamise eesmärgist, mis on riiklikul tasandil kokku lepitud, on eeliseks seegi, et põhimõtteliselt võiks õpilased e-teste teha määratud ajavahemiku jooksul kus ja millal iganes, mis teeb eksamite ja/või tasemetööde sooritamise paindlikumaks ja pingevabamaks. Erinevalt õpilastest on õpetajad nimetanud eelistena peamiselt aja kokkuhoidu, aga ka seda, et e-hindamine aitab muuta tagasisidet kvaliteetsemaks, sest see võimaldab jälgida õpilaste edenemist ajas ning teha õigel ajal kindlaks lüngad teadmistes (Alruwais jt 2018). Seevastu hariduslike eesmärkide seisukohast tõstetakse e-hindamise eelisena esile võimalust luua selliseid ülesandeid, mis paberil ei ole võimalikud või mis võimaldavad esitada informatsiooni lihtsalt ja kiiresti. See omakorda toetab teist laadi või uute 
hariduslike eesmärkide püstitamise ja täitmise võimalust. (Jordan 2013; Kyllonen 2009)

Üldisel üleminekul e-hindamisele tuleb arvestada mitme olulise kitsaskohaga. Olulisimaks neist on õpilaste vähesed arvuti kasutamise kogemused ja oskused (Alruwais jt 2018). Näiteks on Backes ja Cowan (2019) võrrelnud õpilaste tulemusi paber- ja e-testide sooritamisel. Uuringust selgus, et inglise keele e-testide tulemused olid oluliselt halvemad kui pabertestide omad, eriti siis, kui teste tehti esimest korda. Järgmisel korral testitulemuste vahe vähenes. (Backes, Cowan 2019) Seega peaks enne e-hindamise üldist rakendamist kindlaks tegema õpilaste arvuti kasutamise oskuse taseme ehk digipädevuse. Samuti tuleks õpilastele võimaldada testimiskeskkonnaga sarnases keskkonnas ülesannete/testide tegemist piisavalt harjutada ehk testimiskeskkond peab olema neile tuttav.

Kuna õpilaste digipädevust ei ole Eestis varem kontrollitud, oligi (ja on) eesti keele e-testide katsetamise eel kõige suuremateks murekohtadeks just I astme õpilaste valmisolek ja suutlikkus teha e-tasemetööd, seda enam, et tekstiloome osa eeldas (ja eeldab edaspidigi) teksti kirjutamist arvutiga. Põhikooli I astme õpilaste puhul ei saa ka kindel olla, et neil on Hariduse Infotehnoloogia Sihtasutuse ja SA Innove hallatavas eksamite infosüsteemis EIS tegutsemiseks vajalikud kogemused olemas.

Teise olulise kitsaskohana on eri uurijad toonud esile, et vabu vastuseid (seletamine, kirjeldamine, põhjendamine jms) sisaldavate ülesannete ja/või küsimuste hindamine on problemaatiline. See nõuab katsetestides arvuti ja inimeste hinnangute korrelatsiooni võrdlemist ning kahe (inim)hindaja hinnete, punktide või arvamuste võrdlemist (Ridgway jt 2004: 5-6). Nende võrdluste põhjal saab koostada vabade vastuste hindamise alused ning püüda kodeerida vastused selliselt, et võimalikult palju saaks lasta arvutil hinnata. Artiklis kirjeldatud e-hindamise katses hindasid kõiki õpilaste kirjutatud tekste õpetajad e-keskkonnas (EIS) oleva hindamisjuhendi alusel.

Eeltoodule lisaks tuleb arvestada tehniliste probleemidega. Kui korraga teevad e-testi kõik ühe vanuseastme õpilased, siis võib server kokku joosta, internet võib muutuda aeglaseks või isegi kaduda (Kyllonen, 2009). E-testide puhul tuleb arvestada ka petmise võimalusega (Dawson, 2016).

Et kontrollida eespool nimetatud eeliste kehtivust ja probleemide olemasolu põhikooli I astme õpilaste seisukohast ning selgitada välja neile võimetekohaste ülesannete tüübid, katsetati e-testi põhikooli I astme õpilastega. Alljärgnevalt antakse ülevaade katsest ja selle tulemustest. 


\section{Materjal ja meetod}

Esmalt koostati e-tasemetöö, mis koosnes kahest osast. Esimeses osas oli kaks tekstiloomeülesannet ning teises osas kolm lugemis-, kaks kuulamisja kaks õigekeelsusülesannet. Ülesanded koostasid I kooliastme õpetajad ja need sisestati eksamiinfosüsteemi EIS. Kõiki ülesandeid eeltestiti ning pärast eeltestimist korrigeeriti.

E-tasemetöö esimene osa koosnes kahest ülesandest: kirjaliku suhtluse ja jutustava teksti kirjutamise ülesandest, mida hindas hindamisjuhendi järgi kaks hindajat.

- Kirjaliku suhtluse ülesandes (1.1) pidi õpilane kirjutama sõbrale e-kirja, milles tal tuli kutsuda sõber AHHAA-keskuse töötuppa.

- Jutustava teksti kirjutamise ülesandes (1.2) pidi õpilane kirjutama neljast pildist koosneva seeria järgi 70-sõnalise jutustava teksti.

Teine osa koosnes seitsmest arvutihinnatavast ülesandest.

- Esimeses lugemisülesandes (2.1) kasutati kahe valikvastusega (õige-vale) ülesannet, milles tuli e-kirja põhjal otsustada väidete õigsuse üle.

- Teises lugemisülesandes (2.2) kontrolliti kuulutuse mõistmist, kasutades kombineeritud ülesannet: kahe valikvastusega (õigevale) ülesannet ja sobitusülesannet, milles tuli ühendada sõna ja tähendus.

- Kolmas lugemisülesanne (2.3) oli kaardi lugemise ülesanne, milles õpilane pidi kirjelduse järgi märkima kaardile teekonna.

- Neljas ja viies olid kuulamisülesanded (2.4 ja 2.5): aimeteksti kuulamise ülesandes kasutati kolme valikvastusega ülesannet, ilukirjandusteksti kuulamise ülesandes kahe valikvastusega (õigevale) ülesannet.

- Kuues ja seitsmes ülesanne (2.6 ja 2.7) olid õigekeelsuse kohta: esimeses ülesandes kasutati valikvastustega lünkteksti, millega kontrolliti häälikuõigekirjaoskust, teises ülesandes aga avatud lüngaga ülesannet, millega kontrolliti sõnamoodustusoskust.

Pärast e-tasemetööd täitsid õpilased tagasisideküsimustiku, milles nad andsid hinnangu tasemetööle ja oma digivahendite kasutamise sagedusele.

Tasemetööd katsetati 7.-11. oktoobril 2019. aastal. Õpilastel oli kummagi tasemetöö osa tegemiseks aega 60 minutit. Kahe osa vahel oli vaheaeg, tasemetöö osi võis teha ka eri päevadel. Tasemetöö katsetusel 
osales kuuest koolist 249 õpilast, kellest 50,6\% olid poisid ja 49,4\% tüdrukud. $66,3 \%$ oli 3. klassi õpilased ja 33,7\% 4. klassi õpilased.

E-tasemetöö analüüsimisel võeti arvesse ülesande keskmist tulemust, Cronbachi alfat ja näitajat Rir. Cronbachi alfa mõõdab ülesannete reliaablust ja näitab üksikküsimuste korrelatsiooni ülesande sees. Kui Cronbachi alfa jääb alla 0,7 , siis ei ole üksikküsimused/-ülesanded hästi sõnastatud, mistõttu võib olla vastustes palju juhuslikkust. Korrelatsioonikordaja Rir mõõdab ülesande punktide korrelatsiooni ülejäänud ülesannete kogutulemusega ja näitab küsimuse/ülesande eristusjõudu.

\section{I kooliastme e-tasemetööd ja õpilaste digipädevus}

Põhikooli I astme õpilaste emakeele e-tasemetööde katsetuse tulemuste analüüs ja sellel põhinev e-testi arendus jätkuvad kuni mõistliku ning töötava variandi valmimiseni või e-hindamisele ülemineku tähtajani. Järgnevalt kirjeldatakse esmase analüüsi tulemusi.

\subsection{I kooliastme e-ülesannete analüüs}

Tasemetöö eest võis saada kokku 89 punkti. Kõigi õpilaste keskmine tulemus oli 60,4\% (53,8 punkti), standardhälve oli 13,6. Õpilaste soorituse jaotust illustreerib joonis 1 . Kuna tasemetöö on kriteeriumtest, siis on selle eesmärk välja selgitada, kuidas õpilased on omandanud kooliastme õpitulemused. Seega võiks tasemetöö keskmine tulemus olla pigem kõrgem, kuid katsetatud tasemetöö keskmine tulemus näitab, et tasemetöö on pigem keskmise raskusastmega. Tüdrukud sooritasid testi oluliselt paremini kui poisid: tüdrukute keskmine tulemus oli $63,4 \%$, poistel $57,5 \%$. Klasside võrdluses testi tulemustes statistilist erinevust ei olnud: 3. klassi õpilaste keskmine tulemus oli $60,2 \%$, 4. klassi õpilastel $60,8 \%$.

Ülesannete keskmine tulemus jääb vahemikku $42-83 \%$ (vt joonis 2). Kõige lihtsamaks osutusid valikvastustega häälikuõigekirjaülesanne (ül $2.6-83 \%$ ) ja ilukirjandusteksti kuulamise ülesanne (ül 2.5-81\%), kõige raskemaks õige sõnavormi lünkülesanne (ül 2.7-42\%). Suhteliselt madal oli ka pildiseeria ülesande tulemus (ül $1.2-53 \%$ ), mis võis olla tingitud õpilaste kehvast arvuti kasutamise oskusest.

Ülesannete korrelatsioon kogutulemusega (Rit) on võrdlemisi tugev (vt tabel 1), vaid kahe ülesande korrelatsioon oli keskmine: e-kirja lugemise 


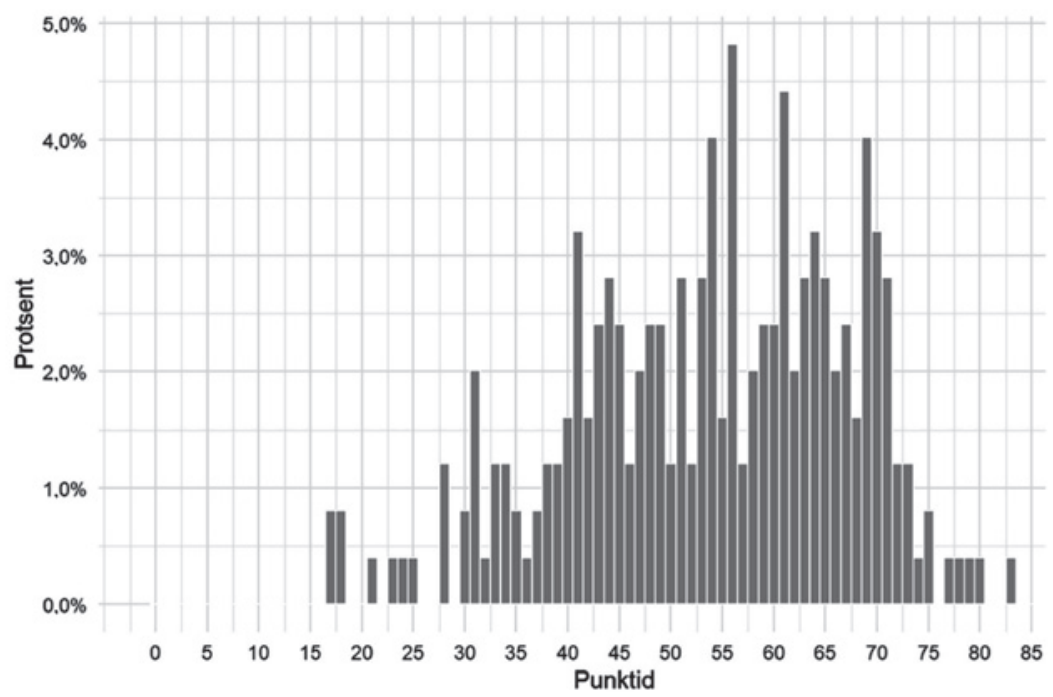

Joonis 1. E-tasemetöö tulemused

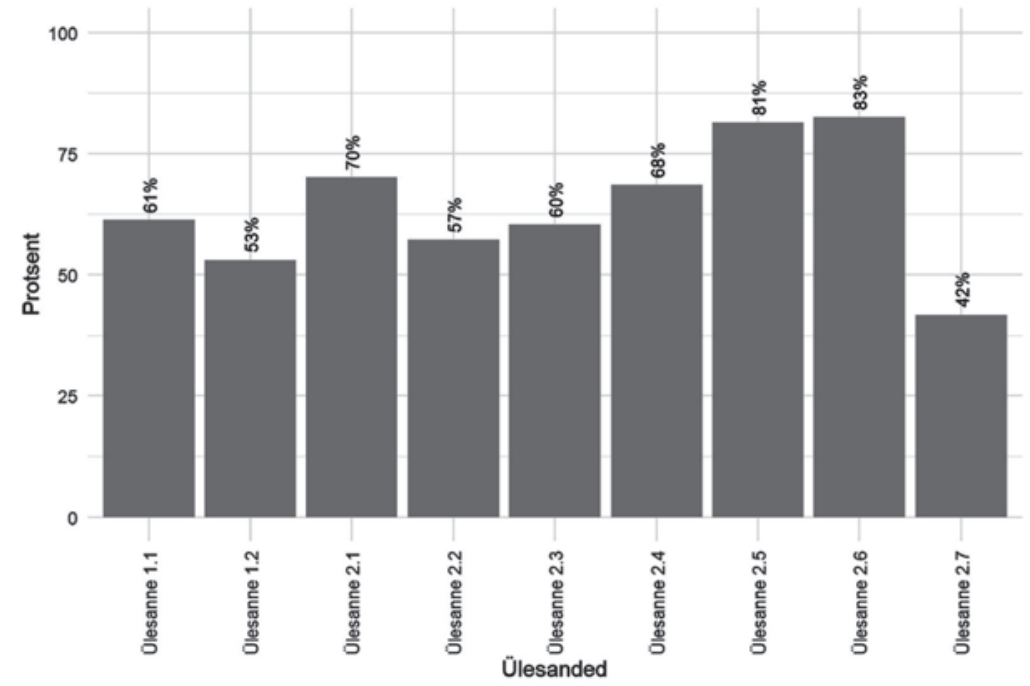

Joonis 2. Ülesannete keskmised tulemused protsentides 
ülesandel (ül 2.1) 0,4 ja ilukirjandusteksti kuulamise ülesandel (ül 2.5) 0,44. Mõlemal juhul kasutati kahe valikvastusega (õige-vale) ülesannet. Sellest võib järeldada, et see ülesandetüüp ei ole tasemetöö jaoks kõige sobilikum. Ülejäänud ülesannete korrelatsioonid jäävad vahemikku $0,59-0,66$.

Tabel 1. Ülesannete statistilised andmed

\begin{tabular}{|c|c|c|c|c|c|c|}
\hline Ülesanne & Min & Keskmine & Max & Standardhälve & Rit & Rir \\
\hline 1.1 & 0 & 61 & 15,5 & 2,7 & 0,59 & 0,44 \\
\hline 1.2 & 0 & 53 & 12 & 2,0 & 0,62 & 0,51 \\
\hline 2.1 & 1 & 70 & 8 & 1,1 & 0,40 & 0,32 \\
\hline 2.2 & 0,5 & 57 & 6 & 1,1 & 0,61 & 0,55 \\
\hline 2.3 & 0 & 60 & 12 & 3,0 & 0,66 & 0,49 \\
\hline 2.4 & 1 & 68 & 7 & 1,6 & 0,65 & 0,57 \\
\hline 2.5 & 0 & 81 & 8 & 1,3 & 0,44 & 0,35 \\
\hline 2.6 & 3 & 83 & 10 & 1,5 & 0,61 & 0,53 \\
\hline 2.7 & 0 & 42 & 10 & 3,2 & 0,63 & 0,44 \\
\hline
\end{tabular}

Korrelatsioonikordaja Rir jäi vahemikku 0,32-0,57. Kõige väiksema eristusjõuga olid õige-vale vastusega ülesanded: e-kirja lugemise ülesanne (ül $2.1-$ Rir $=0,32$ ) ja ilukirjandusteksti kuulamise ülesanne (ül 2.5 Rir $=0,35)$, mis olid keskmise või pigem kergema raskusastmega ülesanded (vastavalt $70 \%$ ja $81 \%$ ). Kõige paremini eristasid õpilasi valikvastustega aimeteksti kuulamise ülesanne (ül 2.4 - Rir =0,57); meediateksti lugemise ülesanne (ül $2.2-\operatorname{Rir}=0,55$ ), milles oli nii õige-vale vastusega ülesanne kui ka sõna ja tähenduse ühendamise ülesanne; valikvastustega häälikuõigekirjaülesanne (ül $2.6-\operatorname{Rir}=0,53$ ) ning pildiseeria järgi kirjutamise ülesanne (ül 1.2 - Rir =0,51).

Ülesannete sisemine reliaablus oli suur (üle 0,7) kahel ülesandel: valikvastustega häälikuõigekirjaülesandel (ül 2.6-0,76) ja õige sõnavormi lünkülesandel (ül $2.7-0,87$ ). Cronbahi alfa oli 0 kaardi lugemise ülesandel (ül 2.3), kuna arvuti on arvanud kaardile märkimise üheks vastuseks, kuigi õpilased pidid ülesande lahendamiseks tegema 12 otsust. Väga väike oli reliaablus ka e-kirja lugemise ülesandel (ül $2.1-0,16$ ).

Õpilaste arvates olid ülesanded keskmise raskusastmega - nii arvas $57,1 \%$ õpilastest. $27,3 \%$ õpilaste arvates olid ülesanded jõukohased ja 
$11,4 \%$ arvates rasked. Ülesanded muudab õpilaste jaoks raskemaks see, kui nad ei ole seda tüüpi ülesandeid varem teinud: 44,5\% õpilastest väitiski, et nad ei ole sarnaseid ülesandeid teinud, ja 43,7\% õpilastest väitis, et nad on sarnaseid ülesandeid teinud mõnikord. Sageli on sarnaseid ülesandeid teinud oma sõnul 9,0\% õpilastest. Kuna ülesanded meenutavad oma tüübilt paberõppevara ülesandeid, siis viitavad õpilaste vastused sellele, et nad ei ole selliseid ülesandeid teinud arvutiga.

\subsection{I kooliastme õpilaste digipädevus õpilaste endi hinnangul}

Põhikooli I astme õpilaste digipädevuse kohta saab teha järeldusi vaid tagasisideküsimustiku põhjal, kuna eraldi seda ei uuritud.

Õpilased kasutavad endi sõnul erisuguseid digivahendeid. Kõige enam kasutatakse nutitelefoni (38,7\% vastajatest), selle järgneb lauaarvuti (20,9\%). Süle- ja tahvelarvutit kasutavad I astme õpilased peaaegu võrdselt (vastavalt 17,3\% ja 17,0\%). Lugerit kasutatakse aga vähem - seda teeb vaid $2,5 \%$ õpilastest. $3,6 \%$ õpilastest aga väitis, et nad ei kasuta ühtki digivahendit.

Digivahendite kasutamise aeg varieerub päris palju: $36,3 \%$ õpilastest väitis, et kasutab digivahendeid iga päev 1-2 tundi, ja 27,8\%, et alla 1 tunni. Seevastu 2-3 tundi kasutab digivahendeid 13,5\%, 3-4 tundi 6,1\% ja üle 4 tunni 9,8\% vastanud õpilastest. Siin tuleb muidugi meeles pidada, et kasutamisaega ei ole mõõdetud, vaid vastused on antud õpilaste endi hinnangul.

Põhikooli riiklikus õppekavas (PRÕK 2011) on alates 2014. aastast kirjas ka digipädevus, mistõttu võiks eeldada, et digivahendeid kasutatakse õppimiseks juba alates I kooliastmest. Seetõttu tahtsime teada, kui sageli kasutavad õpilased digivahendeid õppimiseks koolis, emakeeletunnis ja kodus. Jooniselt 3 on näha, et digivahendeid kasutatakse õppimiseks suhteliselt harva: harvem kui 2-3 korda kuus kasutab koolis 31,8\%, emakeeletunnis 37,1\% ja kodus 38,8\% õpilastest. Digivahendeid ei kasuta koolis $11,8 \%$, emakeeletunnis $16,3 \%$ ja kodus $19,2 \%$ õpilastest. Sageli (igas tunnis või 2-3 korda nädalas) kasutab digivahendeid koolis 38,8\%, emakeeletunnis $25,7 \%$ ja kodus $28,5 \%$ õpilastest. Siit järeldub, et umbes $44 \%$ õpilastest võib e-testide tegemisel hätta jääda, kuna nad ei kasuta arvutit sarnases olukorras. 


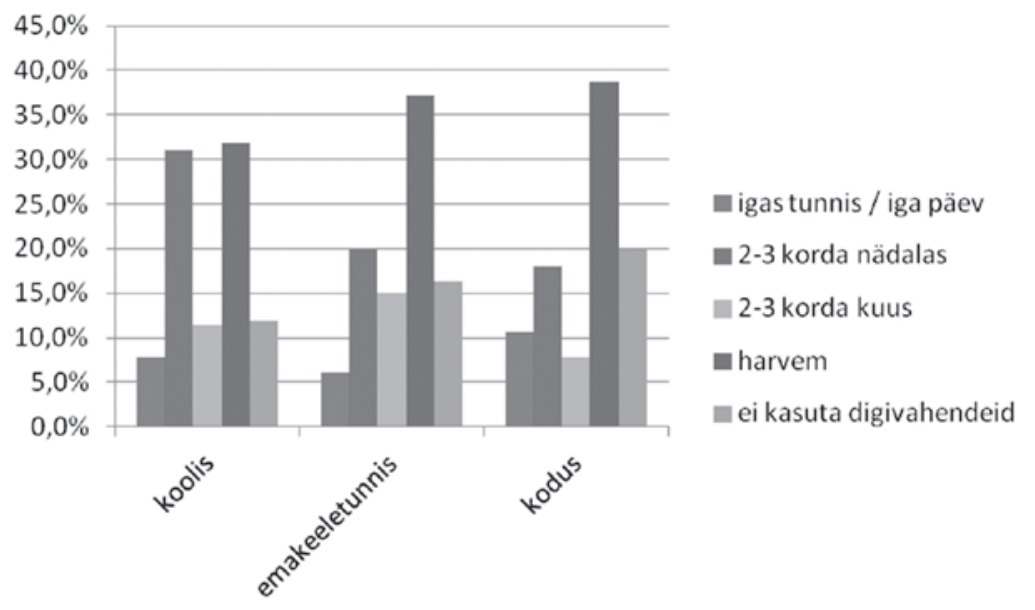

Joonis 3. Digivahendite kasutamine õppimisel õpilaste hinnangul

Tahtsime ka teada, kuidas eelistavad õpilased kirjutada ja lugeda. 41,6\% õpilastest eelistab kirjutada arvutis ja 30,6\% õpilastel ei ole vahet, kas kirjutada käsitsi või arvutis. Ainult 19,6\% I astme õpilastest eelistab kirjutada käsitsi. Tulemus on üpris ootuspärane, kuna käsitsi kirjutamine nõuab rohkem vaeva. Samas ei ole õpilaste digitaalse kirjutamise oskus I astme lõpus kuigi hea - e-kirja kirjutamise ülesandes said õpilased 56\% ja pildiseeria järgi kirjutamise ülesandes $58 \%$ digitaalse kirjutamise oskuse maksimumpunktidest. See näitab, et õpilased saavad kirjutamisega küll hakkama, kuid teevad sageli vigu trükkimisel, unustavad panna tühikuid või ei oska teha suurt algustähte.

Pikkade tekstide lugemisel ei ole $45,7 \%$ õpilaste jaoks vahet, kas loetakse paberilt või digivahendist. Paberilt lugemist eelistab 29,4\% õpilastest, digivahendist lugemist aga $20,8 \%$. Kuna I kooliastmes veel väga pikki tekste ei loeta, siis seetõttu ilmselt ei tajutagi vahet. Samas kasutab lugerit väga vähe õpilasi, nii et tõenäoliselt ei mõelnud õpilased vastamisel raamatute lugemisele. 


\section{Kokkuvõte ja järeldused}

Eesti elukestva õppe strateegias 2020 (HTM 2014) sätestatakse (järkjärgult) üleminek e-hindamisele alates 2021. aastast, seda ka põhikooli I astmes. Et e-tasemetöödega edukalt hakkama saada, peab õpilaste digipädevus olema vajalikul tasemel: nad peavad olema saanud piisavalt harjutada tegutsemist testikeskkonnas ning neil peab olema küllaltki hea arvutiga kirjutamise oskus.

Keele ja kirjanduse valdkonnas e-tasemetööde katsetamise tulemusena soovitigi muu hulgas saada esmased andmed selle kohta, kas ja mis ülesannete lahendamiseks EISi (või muus) e-keskkonnas on õpilased põhikooli I astme lõpus valmis ning võimelised. Seda infot omamata pole selles vanuses õpilastega võimalik üldisele e-hindamisele üle minna, sest riiklikus õppekavas ei ole sätestatud konkreetselt, mis tasemel peab 3. klassi lõpetanud õpilaste digipädevus olema. On vaid üldiselt kirjas, et ,põhikooli I astme õpilane oskab kasutada lihtsamaid arvutiprogramme ning kodus ja koolis kasutatavaid tehnilisi seadmeid“"(PRÕK, 2011), mis ei ole e-testimist silmas pidades eriti nõudlik eesmärk.

I kooliastme eesti keele katsetesti ülesanded olid enamikule õpilastest jõukohased. Samuti olid ülesanded eristusjõulised, kuid edaspidi tuleb üle vaadata väikese eristusjõuga küsimused ja väikese reliaablusega ülesanded ning arvestada uute ülesannete tegemisel nende kitsaskohtadega. Samuti tuli e-testi analüüsist välja, et kahe valikvastusega (õige-vale) ülesanded ei ole eristusjõulised ja on väikese reliaablusega, mistõttu tuleks järgmiste tööde koostamisel selliseid ülesandeid vältida või kombineerida koos teist tüüpi ülesannetega.

E-tasemetöö analüüsi põhjal võime järeldada, et õpilaste arvutioskused on e-ülesannete tegemiseks piisavad, kuna enamik õpilasi kasutab digivahendeid päevas rohkem kui ühe tunni. Samas kasutatakse digivahenditest kõige rohkem nutitelefoni, mis ei anna neile digitaalse kirjutamise oskuse mõttes eelist. Mõtlemiskohaks ongi digipädevuse arendamine koolis. Kuigi juba kuus aastat on digipädevus põhikooli riiklikus õppekavas, siis 44\% e-tasemetööd teinud õpilastest kasutab digivahendeid koolis õppimiseks harva või ei kasuta neid üldse. Kodus õppimisel kasutatakse digivahendeid veelgi vähem $(57,8 \%)$.

Kokkuvõtteks võib öelda, et enne kui I kooliastme õpilased lähevad üle e-tasemetööle, tuleks pöörata suuremat tähelepanu digivahendite 
kasutamisele. Samas võib muutus toimuda ka vastupidi: kui tulevad e-tasemetööd, hakkavad õpetajad oma tundides ka rohkem digivahendeid kasutama. Keskmine lahendusprotsent $(60,4 \%)$ annab aluse arvata, et üleminek e-hindamisele põhikooli I astmes on mõeldav, seda eriti siis, kui koostada selleks sobilikud ja õpilaste digipädevuse taset arvestavad ülesanded.

\section{Kirjandus}

Alruwais, Nuha, Gary Wills, Mike Wald 2018. Advantages and challenges of using e-assessment. - International Journal of Information and Education Technology 8(1), 34-37. doi: 10.18178/ijiet.2018.8.1.1008

Backes, Ben, James Cowan 2019. Is the pen mightier than the keyboard? The effect of online testing on measured student achievement. - Economics of Education Review 68, 89-103. https://doi.org/10.1016/j.econedurev.2018.12.007

Dawson, Phillip 2016. Five ways to hack and cheat with bring-your-own-device electronic examinations. - British Journal of Educational Technology 47 (4), 592-600. https://doi.org/10.1111/bjet.12246

Gilbert, Lester, Denise Whitelock, Veronica Gale 2011. Synthesis report on assessment and feedback with technology enhancement. University of Southampton. https://eprints.soton.ac.uk/273221/ (25.10.2019).

HTM = Haridus- ja Teadusministeerium 2014. Eesti elukestva õppe strateegia 2020. https://www.hm.ee/sites/default/files/strateegia2020.pdf (25.10.2019).

Jordan, Sally 2013. E-assessment: Past, present and future. - New Directions 9 (1), 87-106. http://dx.doi.org/10.11120/ndir.2013.00009

Jürimäe, Maria, Anita Kärner, Leelo Tiisvelt 2014. Kujundav hindamine kui õppimist toetav hindamine. Tartu: Eesti Ülikoolide Kirjastus.

Kyllonen, Patrick C. 2009. New constructs, methods, \& directions for computerbased assessment. -The Transition to Computer-Based Assessment: New Approaches to Skills Assessment and Implications for Large-Scale Testing. Ed. by Friedrich Scheuermann, Julius Björnsson. Luxembourg: OPOCE/OOPEC, 151-156.

PRÕK = Põhikooli riiklik õppekava, 2011. - Riigi Teataja, RT I 14.01.2011, 1. https://www.riigiteataja.ee/akt/114022018008 (10.11.2019).

Ridgway, Jim, Sean McCusker, Daniel Pead 2004. Literature Review of e-Assessment. Bristol: Futurelab.

Reju, Sanday, Aedwale Adesina 2009. Fundamentals of on-line examinations. - Presented at a Training Workshop for Academic Staff on On-line 
Examination System in National Open University of Nigeria, at the Model Study Centre Computer Laboratory.

VV 2014 = Vabariigi Valitsuse 6. jaanuari 2011. a määruse nr 1 „Põhikooli riiklik õppekava“ ja Vabariigi Valitsuse 6. jaanuari 2011. a määruse nr 2 „Gümnaasiumi riiklik õppekava“ muutmine, 2014. - Riigi Teataja, RT I, 29.08.2014, 18. https://www.riigiteataja.ee/akt/129082014018 (10.11.2019).

Vleuten, Cees P. van der, Lambert W. T. Schuwirth, Erik W. Driessen, Marjan J. B. Govaerts, Silvia Heeneman 2015. Twelve tips for programmatic assessment. - Medical Teacher 37 (7), 641-646. https://doi.org/10.310 9/0142159X.2014.973388 


\title{
Inclination and capacity of primary school students to take an e-assessment of native language skills
}

\author{
HELIN PUKSAND, ANNE UUSEN
}

This article gives an overview of a low-stake standardised test pilot study completed at primary school level $(\mathrm{N}=249)$ in October 2019. The pilot study was undertaken as part of the Estonian Lifelong Learning Strategy 2020 (HTM 2014), which prescribes transitioning all general assessments on each education level in Estonia to a digital format. The article presents suggestions for the transition based on the preliminary analysis of the pilot study as well as an overview of the types of assignments that proved to be efficient considering the students' digital capabilities among other things.

The results show that the first stage students of basic school did a good job of taking the e-test. Somewhat surprisingly, the results of the $3^{\text {rd }}$ and $4^{\text {th }}$ grade students were quite similar. The easiest task was spelling with multiple-choice answers and listening to fiction, the most difficult task was to fill the gap with the correct word form.

The average score $(60.4 \%)$ indicates that the transition to e-assessment at the elementary level of primary school is feasible under certain conditions, especially when the results of the pilot study and the students' digital literacy levels are taken into account.

Keywords: e-assessment, standard-determining test, e-test, formative assessment

Helin Puksand

eesti ja üldkeeleteaduse instituut

Tartu Ülikool

Jakobi 2

51014 Tartu

helin.puksand@ut.ee
Anne Uusen

haridusteaduste instituut

Tallinna Ülikool

Narva mnt 25

10120 Tallinn

anne.uusen@tlu.ee 